
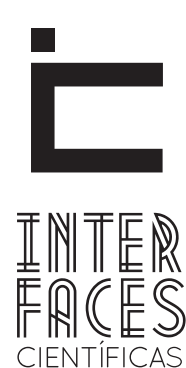

HUMANAS E SOCIAIS

\title{
HETEROSSEXISMO E HETERONORMATIVIDADE COMO REGULAÇ̃̃ES DAS IDENTIDADES SEXUAIS E DE GÊNERO: EFEITOS PRODUZIDOS NO COTIDIANO'.
}

HETEROSEXISM AND HETERONORMATIVITY AS REGULATIONS OF SEXUAL AND GENDER IDENTITIES: EFFECTS DAILY PRODUCED.

HETEROSEXISMOYHETERONORMATIVIDADCOMOREGULACIONES DEIDENTIDADES SEXUALESYGÉNERO:EFECTOSPRODUCIDOSENELCOTIDIANO.

\section{RESUMO}

O estudo teve como objetivo realizar uma análise teórica acerca do heterossexismo e da heteronormatividade como regulações das identidades sexuais e de gênero, destacando os efeitos produzidos no cotidiano da vida social e no cotidiano escolar. Deste modo, buscamos contribuir com referenciais teóricos numa perspectiva de problematizar as regulações heterossexistas e trazer à tona as identidades de gênero e sexualidades que se apresentam como resistências, subversões e enfrentamentos à hegemonia dos padrões heteronormativos. Nesse sentido, priorizamos questionar as regulações de gênero e das sexualidades que se dão na cotidianidade da vida em sociedade; e, interrogar os movimentos curriculares que (re) produzem a heterossexualidade no cotidiano da escola. Esse trabalho caracterizou-se como uma pesquisa bibliográfica e utilizou-se do materialismo histórico dialético enquanto método que perpassou o estudo.

\section{PALAVRAS-CHAVE}

Heterossexismo. Heteronormatividade. Gênero.

Sexualidades.

1 Esse estudo teórico foi elaborado a partir de resultado de pesquisa bibliográfica no âmbito do doutorado em Educação, vinculado ao Programa de Pós-Graduação em Educação da Universidade Federal de Sergipe, Brasil, como parte da fundamentação teórica da tese de doutoramento em fase de elaboração sob a orientação da Professora Dra. Maria Helena Santana Cruz. A versão do texto da tese avaliada e aprovada no Exame de Qualificação em 22 de março do corrente ano foi intitulada: “JUVENTUDES EM CENA: EDUCAÇÃO, TRABALHO E RELAÇÕES DE GÊNERO NO COTIDIANO DO INSTITUTO FEDERAL DE EDUCAÇÃO, CIÊNCIA E TECNOLOGIA DE SERGIPE”. Convém assinalar que o aprofundamento da pesquisa e sistematização final da tese se dará ao longo do processo de doutoramento, com prazo de defesa até março de 2019. 


\section{ABSTRACT}

This study aimed to carry out a theoretical analysis about heterosexism and heteronormativity as sexual and gender identity regulations, highlighting the effects produced in the everyday life of social life and in school daily life. In this way, we seek to contribute with theoretical references with a view to problematizing heterosexist regulations and to bring to the fore the gender identities and sexualities that present themselves as resistances, subversions and confrontations to the hegemony of heteronormative patterns. In this sense, we prioritize to question the regulations of

\section{RESUMEN}

El estudio tuvo como objetivo realizar un análisis teórico acerca del heterosexismo y de la heteronormatividad como regulaciones de las identidades sexuales y de género, destacando los efectos producidos en el cotidiano de la vida social y en el cotidiano escolar. De este modo, buscamos contribuir con referenciales teóricos en una perspectiva de problematizar las regulaciones heterosexistas y traer a la luz las identidades de género y sexualidades que se presentan como resistencias, subversiones y enfrentamientos a la hegemonía de los patrones heteronormativos. En ese sentido, priorizamos cuestionar las regulacio- gender and sexualities that occur in the everyday life of society; and, to question the curricular movements that (re)produce heterosexuality in the daily life of the school. This work was characterized as a bibliographical research and used dialectical historical materialism as a method that pervaded the study.

\section{KEYWORDS}

Heterossexism. Heteronormativity. Gender. Sexualities. nes de género y de las sexualidades que se dan en la cotidianidad de la vida en sociedad; $y$, interrogar los movimientos curriculares que (re)producen la heterosexualidad en el cotidiano de la escuela. Este trabajo se caracterizó como una investigación bibliográfica y se utilizó del materialismo histórico dialéctico como método que traspasó el estudio.

\section{PALABRAS CLAVE}

Heterossexismo. Heteronormatividad. Género.

Sexualidad. 


\section{INTRODUÇ̃̃̃o}

Esse estudo se propôs ao objetivo de realizar uma análise teórica acerca do heterossexismo e da heteronormatividade enquanto regulações das identidades sexuais e de gênero, enfatizando os efeitos produzidos no cotidiano da vida social e no cotidiano escolar. Nessa direção, buscamos contribuir com referenciais teóricos numa perspectiva de problematizar as regulações heterossexistas e trazer à tona as identidades de gênero e sexualidades que se apresentam como resistências, subversões e enfrentamentos à hegemonia dos padrões heteronormativos.

Para esse intento, priorizamos inicialmente realizar uma discussão que nos levasse ao questionamento das regulações de gênero e das sexualidades que se dão na cotidianidade da vida em sociedade. Em seguida, fizemos um recorte do debate sobre regulações e heteronormatividade nos marcos da vida escolar, quando interrogamos os movimentos curriculares que (re)produzem a heterossexualidade no cotidiano da escola. Por fim, demarcamos algumas notas conclusivas que foram captadas no percurso teórico e análises desenvolvidas nesse estudo.

Quanto aos aspectos metodológicos desse estudo teórico, registramos que o trabalho caracterizou-se como uma pesquisa bibliográfica, norteada pela combinação de elementos explicativos e descritivos, sendo predominante a natureza qualitativa desta pesquisa. Utilizamos o levantamento bibliográfico para a coleta de dados que se mostraram relevantes para a discussão teórica a que nos propomos, constituindo-se como procedimento metodológico por excelência na coleta de informações, baseado no objetivo proposto. A análise e interpretação dos dados foram realizadas a partir de categorias definidas durante o estudo à luz do referencial teórico construído no decorrer da investigação. Essa pesquisa utilizou-se do materialismo histórico dialético enquanto método que perpassou o estudo.

\section{QUESTIONANDO AS REGULAÇÕES DE GÊNERO E DAS SEXUALIDADES}

A cotidianidade da vida social é marcada por regulações que adentram distintos espaços de nossas individualidades, haja vista que as determinações estão situadas muito além das relações sociais, chegando inclusive a intervir e regular os parâmetros de nossas condutas afetivas e sexuais, em que o heterossexismo se impõe como a norma regulatória. Nesse sentido, concordamos com a reflexão que Pino (2016, p.33) traz à baila quando alude que

[...] a ordem social na qual vivemos por meio da apropriação de sistemas de opressão como o patriarcado, o racismo e o heterossexismo, estabelece determinações não apenas nas relações sociais, mas ideologicamente nos impõe, interferindo em nossa individualidade, como devemos usufruir de nossos prazeres, desejos e para isso demarca como "aceitável" uma única forma de conduta afetiva e sexual, isto é, com o sexo oposto.

A base do heterossexismo está sustentada por ser configurar enquanto um sistema que organiza as várias dimensões da vida da mulher e do homem social. Há que se registrar que a regulação heterossexista vai além daquilo que associamos a uma imposição em se tratando da orientação sexual (heterossexual), pois se relaciona ao fato da heterossexualidade se estabelecer como uma norma social em muitos outros aspectos da vida: quer sejam os de cunho político, econômico, jurídico, dentre outros (RIOS, 2009; PINO, 2016). Desta feita, o heterossexismo insurge como

[...] um sistema em que a heterossexualidade é institucionalizada como norma social, política, econômica e jurídica, não importa se de modo explícito ou implícito. Uma vez institucionalizado, o heterossexismo manifesta-se em instituições culturais e organizações burocráticas, tais como a linguagem e o sistema jurídico. Daí advém, de um lado, superioridade e privilégios a todos que se adequam a tal parâmetro e de outro, opressão e prejuízos a lésbicas, gays, bissexuais, travestis, transexuais e até mesmo a heterossexuais que porventura se afastem do padrão de heterossexualidade imposto (RIOS, 2009, p.62-63). 
Corroboramos com a premissa de que devemos distinguir a heterossexualidade de uma simples orientação sexual e então concebê-la como um sistema político-ideológico que tem por base as relações sociais, sobretudo aquelas estabelecidas entre homens e mutheres. Pois bem, o alicerce de reprodução e expansão do sistema heterossexista se constitui do "pensamento hetero", este, por sua vez, é concebido como um conjunto de ideias universalizadas em conceitos que procura estabelecer "leis gerais" com o intuito de que sejam aplicadas a todas as sociedades, épocas e indivíduos, e, que são naturalizadas como "norma social" (PINO, 2016; WITTIG, 1980).

É importante assinalarmos que "as pessoas que se adequam aos parâmetros dessa 'norma' social adquirem um status de superioridade e são beneficiados com privilégios” (PINO, 2016, p.33); para as pessoas “[...] consideradas 'fora da norma' sobram opressões e prejuízos em vários âmbitos" ${ }^{4}$. Vimos que a condição de situar-se excluído da norma constitui um paradoxo, posto que "[...] se a norma confere inteligibilidade ao campo social e normatiza esse campo para nós, então estar fora da norma é continuar, em certo sentido, a ser definido em relação a ela" (BUTLER, 2014, p.253). Com isso temos que "não ser totalmente masculino ou não ser totalmente feminina é continuar sendo entendido exclusivamente em termos de uma relação a 'totalmente masculino' e 'totalmente feminina"'5.

Precisamos nos atentar para a questão de que embora "a sociabilidade do capital insista na naturalização de uma única forma de vivenciarmos a nossa sexualidade" (PINO, 2016, p.33), a história nos mostra que as construções sociais, as individualidades e as subjetividades que perpassam a nossa cotidianidade nos legam distintas formas de experimentarmos e vivenciarmos a sexualidade. Portanto, na "realidade da vida cotidiana encontramos diferentes possibilidades de desfrutar a nossa subjetividade afetivo-sexual, pois existe uma diversidade de orientações sexuais e identidades de gênero a serem descobertas e experimentadas".

4 lbid., p.34.

5 lbid., p. 253.

6 Ibid., p. 33.
Em razão disso, salientamos que as nossas "subjetividades, muitas vezes elaboradas culturalmente em determinações heterossexistas, marcam e definem nossos corpos e servem como um ponto de reconhecimento de nós mesmos(as) e dos(as) outros(as)"7. Cabe apontarmos aqui que "[...] o gênero constrói a inteligibilidade do corpo e dos comportamentos no espaço público" (BRETON, 2014, p. 19). Logo, endossamos o pressuposto de que "o masculino e o feminino não existem senão através das repetições, como normas de comportamento e não como absolutos. 0 gênero não está aprisionado no sexo [...]".

Desse modo os nossos corpos podem vir a representar a materialização da sexualidade não obstante isso acabe sendo feito em grande parte dos casos alicerçado nas diferenças mulher-homem. O sexo é socialmente determinado, não se configurando apenas como um mero elemento da natureza, pois apesar de o "sexo biológico" ser comumente reduzido a um órgão sexual e ainda considerado como as marcas "naturais" do feminino e do masculino, registra-se que reivindica a sua declaração com alicerce em comportamentos expressados no corpo, tornando então o indivíduo reconhecível para a sociedade como homem e/ou como mulher. Ressaltamos que dado o processo de construção social estes comportamentos são assimilados no decorrer da infância e adolescência através das referências apresentadas e experenciadas nos espaços de socialização, a exemplo da família, escola e comunidade (CAETANO, 2014; PINO, 2016).

Tem-se que "sexualidade[s], assim como o gênero, são construções sociais, portanto, encarnam a viabilidade de transcender uma visão dualista ou binária do sexo/gênero" (PINO, 2016, p.35), vez que “[...] pode ser construída e vivenciada a partir de múltiplas pos-

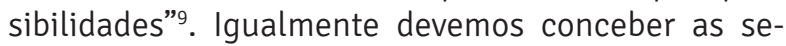
xualidades como "[...] uma potência que desestabiliza a norma das identidades, zomba dos limites dos 'sexos antagônicos' e reelabora as expectativas de gênero" (CAETANO, 2014, p. 40). Isso implica em asseverar-

7 lbid., p.35

8 lbid., p. 19.

9 lbid., p. 35. 
mos que o que não se encaixa no binarismo também é parte do gênero, pois

\begin{abstract}
[...] gênero não é exatamente o que alguém "é” nem é precisamente o que alguém "tem". Gênero é o aparato pelo qual a produção e a normalização do masculino e do feminino se manifestam junto com as formas intersticiais, hormonais, cromossômicas, físicas e performativas que o gênero assume. Supor que gênero sempre e exclusivamente significa as matrizes "masculino" e "feminina" é perder de vista o ponto crítico de que essa produção coerente e binária é contingente, que ela teve um custo, e que as permutações de gênero que não se encaixam nesse binarismo são tanto parte do gênero quanto seu exemplo mais normativo (BUTLER, 2014, p.253).
\end{abstract}

Com base nesses pressupostos contrariamos veementemente a premissa da naturalização do ser mulher e do ser homem. Também nos impulsiona a concordarmos que a construção social do ser mulher e homem "está entrelaçada em um processo social complexo [...] composta pelas várias dimensões de estruturação da sociedade" (PINO, 2016, p.36), demandando, por sua vez, a necessidade de considerarmos que "[...] as significações atribuídas ao feminino e ao masculino são desenvolvidas nas interfaces de relações sociais mais amplas" (CISNE, 2014, p. 116). É imprescindível registrar que mesmo que o gênero seja "[...] o mecanismo pelo qual as noções de masculino e feminino são produzidas e naturalizadas, [...] gênero pode muito bem ser o aparato através do qual esses termos podem ser desconstruídos e desnaturalizados" (BUTLER, 2014, p.253). A abordagem de gênero pode resultar numa forma de reforçar as operações reguladoras ou de rompê-las, posto que um discurso restritivo sobre gênero que insista no binarismo homem e mulher "como a maneira exclusiva de entender o campo do gênero atua no sentido de efetuar uma operação reguladora de poder que naturaliza a instância hegemônica e exclui a possibilidade de pensar sua disrupção"10.

A construção social da sexualidade "não se restringe às significações do ser homem ou mulher" (PINO, 2016, p.36); de igual modo se estende ao conhecimento "científico" difundido sobre sexo que

10 Ibid., p.254, grifo original. acabam por "controlar as suas significações atribuindo-lhes normatizações, patologias e legitimidades, que podem [...] reprimir determinadas expressões da sexualidade ou retirá-las da denominação da anormalidade"11, a depender, obviamente, da sociedade e período histórico que marcam o desenvolvimento e a difusão desses conhecimentos.

Ante o exposto, temos que a sociedade capitalista estrutura-se a partir da correlação de forças não apenas das relações sociais de classe, mas igualmente por correlação de forças das relações de sexo. É baseada na estrutura das relações sociais de sexo e divisão sexual do trabalho que a sociedade se organiza fundamentada numa composição patriarcal em que a heterossexualidade é naturalizada como sendo a única orientação "normal”. Nesse sentido, é imperioso destacarmos que quando ocorre o fato de duas pessoas do mesmo sexo se amarem e/ou se relacionarem sexualmente isso implica em ruptura com uma "norma social", diga-se, a norma da heterossexualidade, a heteronormatividade (PINO, 2016).

Sendo assim, a heterossexualidade se estabelece como um dos pilares do patriarcado, consequentemente se impõe como modelo normativo de relações. Vale pontuarmos que enquanto modelo pode até mesmo se perpetrar nas relações entre casais homoafetivos, notadamente nos casos em que determinados papeis pautados na divisão sexual do trabalho são instituídos na dinâmica da relação. Portanto, quando se naturaliza a heterossexualidade como o único modelo possível no âmbito das relações sociais, sexuais e afetivas cotidianas, o que vier a ser construído socialmente diferente dessa lógica heterossexista acaba por ocupar uma posição de estar à margem da "norma”, cujas categorizações dadas são aquelas de “anormal”, “desvio”, “problema” (PINO, 2016).

Apesar de a sociedade capitalista patriarcal buscar intensificar o "enquadramento" do gênero humano ao padrão heterossexista, demarcamos que as diferenças subjetivas dos sujeitos constroem a diversidade como modo de ser que foge a este enquadramento,

11 lbid., p. 36 
enquanto expressão constituinte das individualidades desses sujeitos (PINO, 2016). É então através das manifestações dessas individualidades que os sujeitos sociais "[...] revelam singularidades, apresentam diferenças em seu modo de ser, de se apropriar, de se adaptar ou de buscar transformar as relações vigentes" (SANTOS, 2009, p. 76). Por isso a importância de nos atentarmos para a necessidade de pensarmos a diversidade sexual como

[...] mais que uma variedade de formas no leque das orientações e identidades. [...] é fundamental pensarmos a diversidade sexual como uma concepção que impõe questionamentos à compreensão da heterossexualidade como única possibilidade de manifestação da sexualidade em detrimento das várias maneiras de se sentir prazer, de usar o corpo e expressar afeto (PINO, 2016, p.41).

Dados esses supostos, capturamos como essência o sentido das resistências e subversões às normas heterossexistas enquanto mecanismos que questionam a naturalidade do masculino e feminino como formas hegemônicas que justificam a heterossexualidade. Esses questionamentos se dão a partir de inúmeras formas de experenciar e manifestar as sexualidades, haja vista que na relação entre orientação sexual e identidade de gênero existem diversas possibilidades de sexualidades: homossexualidades, lesbianidades, bissexualidades, heterossexualidades, travestilidades, transexualidades e outras que ainda não foram nomeadas. Assim, as correlações que emergem entre as orientações e identidades possuem a capacidade de contestar política e socialmente a "naturalidade" propagada do masculino e do feminino usada para justificar a heterossexualidade (PINO, 2016; BRETON, 2014).

\section{INTERROGANDO OS MOVIMENTOS CURRICULA- RES QUE CREJPRODUZEM A HETEROSSEXUALI- DADE NO COTIDIANO DA ESCOLA}

Convém elucidar que os saberes médico, jurídico e religioso se destacaram na disputa pela "ver- dade" a respeito da sexualidade, mesmo que para essa disputa tenham sido usados meios distintos e os motivos tenham sido diferentes. É imperioso registrarmos também a presença e a importância dos saberes e instrumentos pedagógicos e curriculares que foram e ainda são utilizados pelos demais saberes enquanto veículo de prevenção, de repressão e/ ou de correção das práticas nomeadas como anormais (CAETANO, 2013; FOUCAULT, 2001).

A escola com seus instrumentos é vista por Foucault (2001) como o lugar de correção; então, a concebe como o espaço por excelência das pedagogias preventivas e coercitivas, ou seja, como laboratório de construção no corpo dos currículos. Nessa direção assevera que o "campo da anomalia vai se encontrar desde bem cedo [...] atravessado pelo problema da sexualidade [...]" (FOUCAULT, 2001, p.211). Pondera ainda que "[...] esse campo geral da anomalia vai ser codificado, policiado, vão lhe aplicar logo, como gabarito geral de análise, o problema"12.

A primazia da heterossexualidade se constituiu "como a sexualidade-referência depois da instituição da homossexualidade. A heterossexualidade só ganha sentido na medida em que se inventa a homossexualidade" (LOURO, 2009, p.89, grifos originais). Uma primazia que se estabelece como sendo natural pela prerrogativa disseminada de que os sexos anatômicos, os gêneros e a sexualidade são dimensões essencialmente naturais. Em razão deste cenário de referência que vai se impondo muitos sujeitos "consideram que os significados em torno dos sexos anatômicos, dos gêneros e da sexualidade são dimensões que todos nós, mulheres e homens, possuímos 'naturalmente"" (CAETANO, 2013, p.68). Precisamos demarcar que este quadro "[sendo assumido] como verdade, fica sem sentido argumentar a dimensão social, cultural, política, geográfica e histórica, ou seja, os princípios construídos dos sexos e das sexualidades"13.

Segundo esses supostos, tanto os significados dos sexos como os das sexualidades se caracterizariam como algo “dado" pela natureza, consequentemente

12 lbid., p. 211.

13 Ibid., p. 68. 
seria marcado e inerente ao ser humano. Essa concepção se fundamenta no corpo e principalmente na suposição de que todos/as vivemos nossos corpos universalmente da mesma forma. Contudo, estes efeitos de naturalidade dos gêneros e das identidades sexuais são performativos e são ainda dotados de poderes de produzir aquilo que nomeia. Desse modo, acabam por repetir e reiterar as normas heterossexuais e androcêntricas. Tem-se que é esse alinhamento entre sexo-gênero-sexualidade que dá sustentação ao processo de heteronormatividade, isto é, sustentação à produção e também à reiteração compulsória da norma heterossexual (CAETANO, 2013; BUTLER, 2003; LOURO, 2000, 2009).

Registra-se que a heteronormatividade só vem a ser reconhecida como "um processo social, ou seja, como algo que é fabricado, produzido, reiterado, e somente passa a ser problematizada a partir da ação de intelectuais ligados aos estudos de sexualidade [...]" (LOURO, 2009, p.90, grifos originais). Assim, os estudos gays, lésbicos e a teoria queer, isto é, as mulheres (lésbicas, bissexuais e heterossexuais), os gays, bem como outros grupos cujas sexualidades se definem em oposição à heteronormatividade se constituem como os primeiros a problematizarem as diferenças de gênero, estabelecendo-se, portanto, como os precursores a explorar a política da sexualidade ou a sexualidade como política. Desta feita, ao apresentar os questionamentos aos juízos mais elementares sobre o sexo, o gênero e a sexualidade, incluídas aí as oposições binárias heterossexual/homossexual, sexo biológico/gênero e homem/mulher, esses estudos bem como os coletivos desses sujeitos desenvolveram como resultados novas formas de examinar o tema da identidade humana, resultados que também refletem e provocam problematizações nas políticas e movimentos curriculares (LOURO, 2009; CAETANO, 2013).

Considerando a premissa de que a heteronormatividade se constitui como algo fabricado, produzidoe reiterado, tendo como aparato para este processo o recurso dos movimentos curriculares, daremos ênfase aos movimentos curriculares que se dão no interior da escola. Por movimentos curriculares estamos concebendo
[...] as pedagogias escolares e as tecnologias pedagógicas (arquitetura, livros didáticos, vestimentas, mídia etc.), que significadas na cultura e obedecendo a certa lógica de planejamento, constroem, ensinam e regulam as corporalidades, produzindo modos de subjetivações e arquitetando formas e configurações de estar e viver na escola e, logicamente, na sociedade (CAETANO, 2013, p.66).

Entendendo o corpo como "a base onde o conhecimento é significado e é ele o lócus em que parte a produção e a expressão da cultura" ${ }^{14}$, implica conceber a evidência de que as sexualidades e os gêneros "ganham significados e reafirmam a necessidade de problematizar os movimentos curriculares, à medida que eles são parte dos dispositivos pelos os quais a escola executa a formação de seus sujeitos"15. Concordamos com a ponderação de Caetano (2013, p.67) quando nos chama a atenção para o fato de que "[...] transitam modelos de gêneros nos [movimentos curriculares cotidianos] [...] e estes projetam a heterossexualidade e a masculinidade hegemônicas como norma e referência". É pertinente ressaltarmos que "as muitas formas de fazer-se mulher ou homem, as várias possibilidades de viver prazeres e desejos corporais são sempre sugeridas, anunciadas, promovidas socialmente" (LOURO, 2000, p.5); essas formas “[...] são também, renovadamente, reguladas, condenadas ou negadas" ${ }^{16}$. Esse processo se dá estreitamente vinculado às relações de poder presentes e em exercício na dinâmica da sociedade.

Portanto, corroboramos com a reflexão trazida à baila de que

[...] os movimentos curriculares fazem parte [das] práticas educativas que nos ensinam a heteronormatividade e 0 androcentrismo. Esses dois dispositivos são constituídos por regras discursivas que produzidas nas sociedades atravessam suas tecnologias educativas e interpelam nossas subjetividades permitindo, com isto, o controle ou a mediação da forma como vivemos nossos gêneros, sexualidades e nos posicionamos nos espaços sociais. Para tanto, estes

14 Ibid., p.67, grifo original.

15 Ibid., p. 67.

16 lbid., p. 5. 
discursos e interpelações precisam ser constantemente repetidos e reiterados nas práticas educativas cotidianas para dar o efeito de substância e de algo natural (CAETANO, 2013, p.68).

No ambiente escolar o processo de "reiteração da heterossexualidade adquire consistência (e também invisibilidade) exatamente porque é empreendido de forma continuada e constante (muitas vezes, sutil) pelas mais diversas instâncias sociais" (LOURO, 2009, p.90). Não obstante "os discursos mais autorizados nas sociedades contemporâneas [reiterem] a norma regulatória que supõe um alinhamento entre sexo-gênero-sexualidade"17, na sociedade de igual modo “[...] circulam [...] (e cada vez com mais força) discursos divergentes e práticas subversivas dessa norma [...]"18. O recomendado em uma sociedade escriturária, denominada como aquela que define as regras, emerge como fruto do seu meio e dispõe da capacidade de transformar a carne, ou seja, o indivíduo sem as normas coletivas, em um corpo social, dito de outro modo: naquele indivíduo produzido pelas normas e regras da sociedade, que em consequência dessa transformação será este o corpo social aceito. Portanto, a escola, enquanto parte da estrutura da sociedade, também assume, por meio dos seus movimentos curriculares, um papel na construção desse corpo social, já que ela igualmente "tatua" na carne as normas, transformando esse corpo em um corpo socialmente aceito (CERTEAU, 1994; CAETANO, 2013).

Vale ressaltarmos que os movimentos curriculares “(re) produzem certo entendimento de masculinidade e feminilidade no interior do qual são formados os [indivíduos em sociedade e no caso do cotidiano escolar] seus alunos e alunas" (CAETANO, 2013, p.75), atravessando assim a vida cotidiana. Aqui damos destaque aos movimentos curriculares que atravessam a vida cotidiana escolar, haja vista que a escola "pratica a pedagogia da sexualidade, o disciplinamento dos corpos. Tal pedagogia é muitas vezes sutil, discreta, contínua mas, quase sempre, eficiente e duradoura" (LOURO, 2000, p.10).

17 lbid., p. 90.

18 lbid., p. 90.
Salientamos que como resultado da pedagogia da sexualidade emergem a vigilância e as práticas educativas no corpo como mecanismos fundamentais para corrigir o que se acusa de "comportamento estranho" e "anormal". A escola se apresenta como uma instância consideravelmente responsável pela manutenção e criação das hierarquizações geradas a partir das ideias de masculinidade e feminilidade, e, ainda que não seja a única responsável seus movimentos curriculares exercem significativa relevância na produção e reprodução dos projetos de masculinidades e feminilidades hegemônicos que se balizam nos papeis sexuados atribuídos historicamente aos homens e às mulheres. Por meio dos instrumentos oficiais curriculares e nas ações cotidianas da e na escola nota-se que as apresentações, estigmatizadas ou não, orientam as avaliações realizadas em torno dos sujeitos. Em decorrência disso muitas das marcas das vivências escolares relacionam-se a episódios, fatos e experiências de como construímos nossas identidades sociais, sobretudo as identidades de gênero e também as identidades sexuais (CAETANO, 2013; LOURO, 2000). Com estas argumentações demarcamos em concordância com Louro (2000, p. 13) que não pretendemos

[...] atribuir à escola nem o poder nem a responsabilida-
de de explicar as identidades sociais, muito menos de
determiná-las de forma definitiva. É preciso reconhe-
cer, contudo, que suas proposições, suas imposições
e proibições fazem sentido, têm "eleitos de verdade",
constituem parte significativa das histórias pessoais.

Através do jogo de apresentações e especialmente das expectativas heteronormativas de gênero as identidades dos indivíduos são estigmatizadas, notadamente os maiores estigmas direcionam-se às identidades LGBT's (Lésbicas, Gays, Bissexuais, Travestis e Transexuais) que subvertem às lógicas heterossexistas, que por serem inscritas e significadas no corpo encontramse no interior das hierarquizações e classificações sociais, e, de igual modo nas práticas curriculares, incidindo mais vastamente nas ações e relações escolares. O discurso de gênero é constituído e significado como 
efeito de sofisticados equipamentos educativos e formativos que são produzidos e mantidos por instituições como o direito, a medicina, a família, a escola, a religião e a língua, que, por sua vez, produzem corpos reconhecidos e identificados como masculinos e outros como femininos. Essa dinâmica obscurece e oculta outras possibilidades de estruturação e construção das identidades e práticas sexuais (CAETANO, 2013).

É imprescindível ressaltarmos que "através de múltiplas estratégias de disciplinamento, aprendemos a vergonha e a culpa; experimentamos a censura e o controle" (LOURO, 2000, p.18). Nesse cenário, por sua vez, vamos nos construindo "acreditando que as questões da sexualidade são assuntos privados, [deixando] de perceber sua dimensão social e política" ${ }^{19}$. Cabe demarcarmos ainda que "meninos e meninas aprendem, [...] desde muito cedo, piadas e gozações, apelidos e gestos para dirigirem àqueles e àquelas que não se ajustam aos padrões de gênero e de sexualidade admitidos na cultura em que vivem" ${ }^{20}$, aprendizados que tem implicações e reflexos na cotidianidade da vida escolar.

Não podemos deixar de pontuar que o "[...] quadro de hostilidade às sexualidades 'desajustadas' à lógica da heteronormatividade é capaz de gerar inúmeras situações de violências cotidianas” (CAETANO, 2013, p.77), inclusive é preciso atentar para o fato de que muitas não se encontram nas estatísticas por estarem sendo vivenciadas em silêncio, demandando que esse quadro de violências cotidianas seja não apenas denunciado e problematizado, mas disponha de intervenção substancial e urgente a fim de romper com a naturalização das práticas LGBTfóbicas presentes no cotidiano da vida social, por conseguinte, da vida escolar.

\section{NOTAS CONCLUSIVAS}

Vimos que a lógica heterossexista sustentada pela heteronormatividade perpassa diferentes dimensões da vida cotidiana, atravessando aspectos políticos, sociais, culturais, sexuais e muitos outros.

19 lbid., p. 18.

20 lbid., p.19.
Captamos que as múltiplas formas de viver e manifestar os prazeres e desejos corporais são originadas e construídas socialmente, contrariando a primazia da naturalidade que thes são atribuídas.

Depreendemos que os corpos atribuídos aos homens e às mulheres são regulados desde a infância, tendo seus desdobramentos e implicações no cotidiano da vida social e também da vida escolar, pois essas regulações e atribuições do que deve ser próprio de menino e de menina, de homem e de mulher, isto é, de como percebemos e decodificamos as marcas dos corpos dos indivíduos influencia na forma como classificamos e julgamos determinados sujeitos pelo modo como se apresentam corporalmente. A forma como os indivíduos se apresentam corporalmente deve ser capturada em nossa concepção enquanto modos distintos de ser e de viver suas identidades de gênero e identidades sexuais legitimamente e não como um mecanismo de vigilância cotidiana que classificam como anormais, patológicas e pecaminosas suas identidades e práticas sociais.

No entanto, no caso daqueles/as que não atendem ao padrão da heteronormatividade, diga-se, que contrariam e subvertem os investimentos provenientes de uma pedagogia da sexualidade heterossexista, já que não constroem suas identidades de gênero e sexuais com referência na dicotomia heterossexual de homem e mulher, reservam-lhe os processos de exclusão, discriminação e opressão cotidianos porque são vistos como sujeitos “anormais" e "desajustados", bem como desse modo são classificadas suas sexualidades.

Por isso enfatizamos neste estudo a necessidade de discussão da regulação das identidades de gênero, das sexualidades e dos corpos no cotidiano da vida social e também os efeitos desse processo de regulação no cotidiano da vida escolar, trazendo para a centralidade do debate a opressão vivenciada por aqueles/ as que apresentam corpos que se diferenciam daquilo que hegemonicamente atribuem aos corpos que atendem à lógica da heteronormatividade. Convém demarcar que na medida em que esses/as subvertem as regulações de masculinidades e feminilidades que thes são impostas, discriminação, preconceito e opressão 
passam a ser vivenciadas, sentidas e sofridas em seu cotidiano. Em se tratando do cotidiano escolar, cabe ressaltarmos que essas opressões são causas que aparecem como justificativas do abandono das trajetórias escolares de muitos/as estudantes, nos levando à necessidade de problematizarmos a LGBTfobia no contexto educacional e também priorizarmos os mecanismos de enfrentamentos a este cenário hostil e perverso, enquanto compromissos de pesquisas e estudos que se colocam na ordem do dia e como compromissos de bandeiras e lutas cotidianas que julgamos importantes de serem encampadas.

\section{REFERÊNCIAS}

BRETON, David Le. Corpo, Gênero, Identidade. In: FERRARI, Anderson et al. (Org.). Corpo, gênero, sexualidade. Lavras: UFLA, 2014.

BUTLER, Judith. Problemas de gênero: feminismo e subversão da identidade. Rio de Janeiro, Civilização Brasileira, 2003.

BUTLER, Judith. Regulações de gênero. Cadernos

Pagu, n.42, janjun., 2014, p. 250274. Disponível em: http://dx.doi.org/10.1590/0104-8333201400420249.

Acesso em: 27 dez. 2016.

CAETANO, Márcio. Movimentos curriculares e a construção da heteronormatividade. In: RODRIGUES, Alexsandro; BARRETO, Maria Aparecida Santos Corrêa. (Org.). Currículos, gêneros e sexualidades: experiências misturadas e compartilhadas. Vitória, ES: Edufes, 2013, p.63-82.

CAETANO, Márcio. "Não se nasce mulher" - ela é performatizada: sexo, política e movimentos curriculares. In: FERRARI, Anderson et al. (Org.).

Corpo, gênero, sexualidade. Lavras: UFLA, 2014.

CERTEAU, M. A invenção do cotidiano: Artes de fazer. Petrópolis-RJ: Vozes, 1994.
CISNE, Mirla. Feminismo e consciência de classe no

Brasil. São Paulo: Cortez, 2014.

FOUCAULT, Michel. Os anormais. Rio de Janeiro: Martins Fontes, 2001.

LOURO, Guacira Lopes. Pedagogias da sexualidade. In: LOURO, Guacira Lopes. (Org). 0 corpo educado: pedagogias da sexualidade. 2 ed. Belo Horizonte: Autêntica, 2000, p.4-24.

LOURO, Guacira Lopes. Heteronormatividade e Homofobia. In: JUNQUEIRA, Rogério Diniz (Org.).

Diversidade sexual na educação: problematizações sobre a homofobia nas escolas. Brasília: Ministério da Educação, Secretaria de Educação Continuada, Alfabetização e Diversidade, UNESCO, 2009, p.85-93.

\section{PINO, Aline Muras de Oliveira. Diversidade sexual} e educação: direitos LGBTs no IFRN Macau. 2016. Dissertação (Mestrado em Serviço Social) - Universidade do estado do Rio Grande do Norte, Mossoró. 143p.

RIOS, Roger Raupp. Homofobia na perspectiva dos direitos humanos e no contexto dos estudos sobre preconceito e discriminação. In: JUNQUEIRA, Rogério Diniz (Org.) Diversidade sexual na educação: problematização sobre homofobia nas escolas. Brasília: Ministério da Educação, Secretaria de Educação Continuada, Alfabetização e Diversidade, UNESCO, 2009, p.53-83.

SANTOS, Silvana Mara Morais. Direitos, desigualdade e diversidade. In: Política social no capitalismo: tendências contemporâneas. 2 ed. São Paulo: Cortez, 2009.

WITTIG, Monique. 0 pensamento hétero. 1980. Disponível em: https://we.riseup.net/ assets/134062/Wittig,+Monique+O+pensamento+He tero_pdf.pdf. Acesso em: 11 jan. 2017. 
2 Assistente Social do Instituto Federal de Educação, Ciência e Tecnologia de Sergipe (IFS). Graduada em Serviço Social pela Universidade Federal de Sergipe (UFS/2009). Especialista em Escola e Comunidade (UFS/2010). Mestra em Serviço Social (UFS/2014). Doutoranda em Educação (UFS/2015). Endereço: Travessa Visconde de Maracaju, 60, 18 do Forte, CEP: 49072-103, Aracaju - SE, Brasil. E-mail: paulajcbrasil@yahoo.com.br. Telefone: (79) 99918-7871.

3 Professora Emérita da Universidade Federal de Sergipe (UFS). Atualmente é professora dos Programas de Pós-Graduação em Educação (NPGED) e Serviço Social (PROSS) da UFS. Pós-Doutora em Sociologia da Educação. Doutora e Mestra em Educação (UFBA). Especialização em Psicologia; Especialização em Modelos de Prática nos Campos de Aplicação do Serviço Social; Especialização em Ciências Sociais. Endereço institucional: Universidade Federal de Sergipe, Centro de Ciências Sociais Aplicadas, Departamento de Serviço Social, Avenida Marechal Rondon, S/N, Cidade Universitária Prof. José Aloísio de Campos,Jardim Rosa Elze, CEP: 49100-000, 
